\title{
TUMORES PARDOS EN MÚLTIPLES LOCALIZACIONES: MANIFESTACIÓN DE HIPERPARATIROIDISMO SECUNDARIO*
}

\author{
Drs. Francisco Rodríguez V. ${ }^{1,3}$, Martín Nicola S. ${ }^{1}$, Oscar Venegas R. ${ }^{1}$, \\ Rocío Nieme B. ${ }^{2}$, Eduardo Osses Z. ${ }^{2}$, Fernanda Häberle O. ${ }^{3}$
}

1 Servicio de Cirugía, Hospital de La Serena.

2 Unidad de Imaginología, Hospital de La Serena.

3 Facultad de Medicina Universidad Católica del Norte.

Chile.

\section{Brown tumors in multiple locations: manifestation of secondary hyperparathyroidism}

Hombre de 46 años con antecedente de HTA desde los 15 años con mala adherencia al tratamiento. El año 2006 se diagnostica hipotiroidismo, dislipidemia mixta y diabetes mellitus tipo 2. Desarrolló Insuficiencia Renal Crónica (IRCr) terminal iniciando hemodiálisis trisemanal el año 2007. En exámenes de control se pesquisa hormona paratiroidea (PTH) de $1.828,6 \mathrm{pg} / \mathrm{ml}$ compatible con hiperparatiroidismo severo. Ecotomografía tiroidea evidencia un nódulo sólido en el extremo distal del lóbulo tiroideo derecho, hipoecogénico que impresiona corresponder a glándula paratiroidea hiperplásica (Figura 1). Presenta aumento de volumen clavicular derecho y costal izquierdo, se completa estudio con TC de Tórax que muestra lesiones osteolíticas en dichas localizaciones con características radiológicas de tumores pardos (TP) (Figuras 2 y 3). En quirófano se identifica paratiroides hiperplásica (Figura 4), se realiza paratiroidectomía total y reimplante de $1 / 4$ en ECM. Los TP son una variante de osteítis fibrosa quística, raramente reportados en pacientes con IRCr, con una incidencia que va de 1,5 a $1,7 \%{ }^{2}$. Son lesiones óseas benignas, expresión de un remodelado óseo acelerado, secundario a niveles persistentemente elevados de $\mathrm{PTH}$, que determinan un incremento

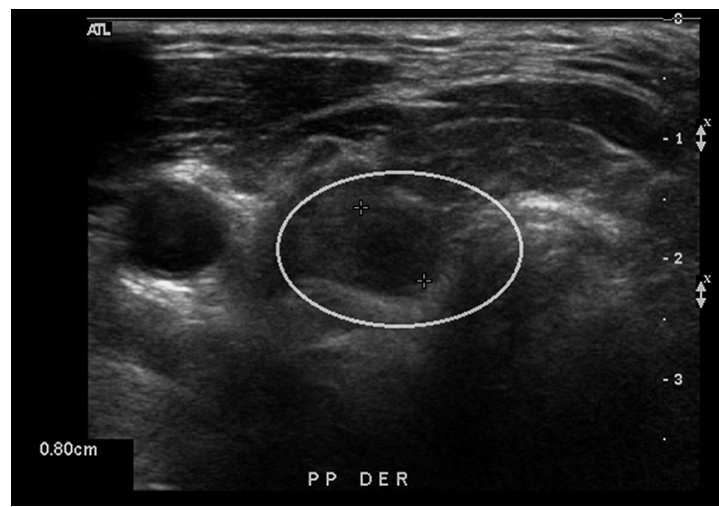

Figura 1. Ecotomografía Tiroidea. Nódulo sólido hipoecogénico, redondeado de $8,0 \times 8,4 \mathrm{~mm}$ en el extremo distal del lóbulo tiroideo derecho correspondiente a glándula paratiroides hiperplásica.

*Recibido el 11 de agosto de 2013 y aceptado para publicación el 10 de octubre de 2013.

Los autores no refieren conflictos de interés.

Correspondencia: Dr. Francisco Rodríguez V.

frv014@alumnos.ucn.cl 


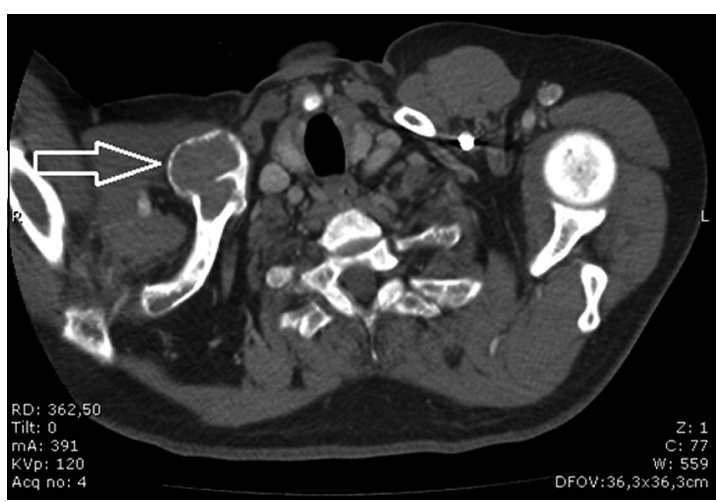

Figura 2. Tomografía Computada de Tórax. Lesión osteolítica expansiva localizada en el extremo proximal de la clavícula derecha (flecha).

en la actividad osteoclástica y fibrosis peritrabecular progresiva $^{2}$. Al suprimir la PTH con la cirugía, se produce calcificación y regresión de los $\mathrm{TP}^{3}$.

\section{Referencias}

1. Ben L, Barbouch S, Hamida B, Abdallah B, Karima K, Imed $\mathrm{H}$, et al. Brown Tumors in Patients with Chronic Renal Failure and Secondary Hyperparathyroidiusm: Report of 12 Cases. Saudi J Kidney Dis Transpl. 2010;21;772-7.

2. Gómez MC, Riquelme P, Sirandoni G, Sapunar J, Princic E, Lee B. Tumores pardos en múltiples localizaciones: manifestación de osteodistrofia renal severa. Caso Clínico. Rev Med Chile 2003;131:1183-7.

3. Fordham CC, Williams TF. Brown tumor and secondary hyperparathyroidism. N Engl J Med. 1993;269:129-31.

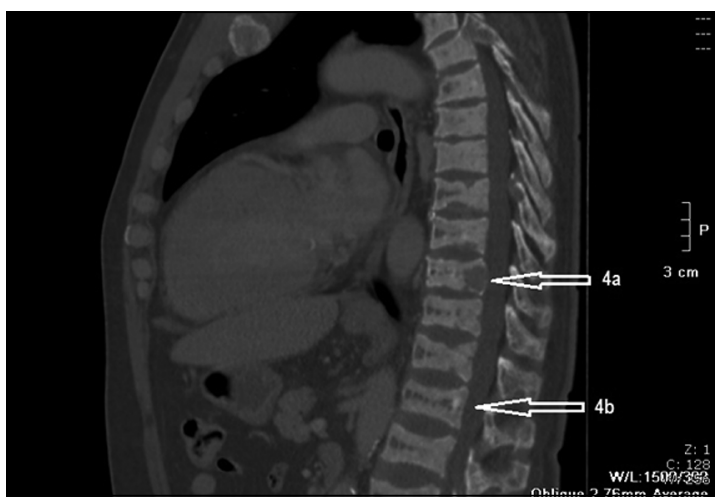

Figura 3. Tomografía Computada de Tórax. Lesiones óseas líticas en los cuerpos vertebrales T10 (4a) y T12. En el resto de la columna dorsal existe esclerosis en banda de las superficies superior e inferior de los cuerpos vertebrales con aspecto radiológico de "camiseta de rugby" (4b).

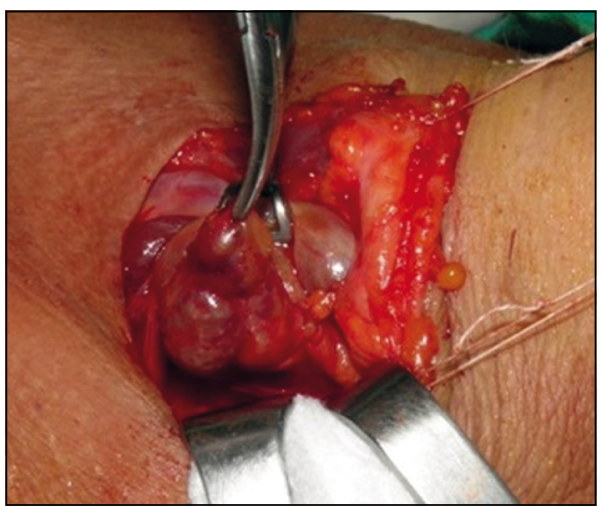

Figura 4. Se identifica paratiroides hiperplásica. Se realiza paratiroidectomía total y reimplante de 1/4 en ECM. 